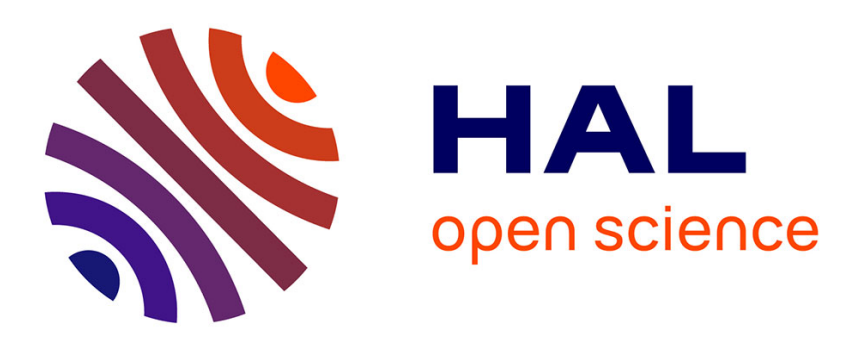

\title{
Standardising Public Policy Documentation to Foster Collaboration Across Government Agencies
}

Mohamed Adel Rezk, Mahmoud H. Aliyu, Hatem Bensta, Adegboyega Ojo

\section{To cite this version:}

Mohamed Adel Rezk, Mahmoud H. Aliyu, Hatem Bensta, Adegboyega Ojo. Standardising Public Policy Documentation to Foster Collaboration Across Government Agencies. 18th Working Conference on Virtual Enterprises (PROVE), Sep 2017, Vicenza, Italy. pp.466-477, 10.1007/978-3-319-651514_42. hal-01674897

\section{HAL Id: hal-01674897 https://hal.inria.fr/hal-01674897}

Submitted on 3 Jan 2018

HAL is a multi-disciplinary open access archive for the deposit and dissemination of scientific research documents, whether they are published or not. The documents may come from teaching and research institutions in France or abroad, or from public or private research centers.
L'archive ouverte pluridisciplinaire HAL, est destinée au dépôt et à la diffusion de documents scientifiques de niveau recherche, publiés ou non, émanant des établissements d'enseignement et de recherche français ou étrangers, des laboratoires publics ou privés. 


\title{
Standardising Public Policy Documentation to Foster Collaboration across Government Agencies
}

\author{
Mohamed Adel Rezk, Mahmoud H. Aliyu, Hatem Bensta and Adegboyega Ojo \\ ${ }^{1}$ Insight Centre for Data Analytics, National University of Ireland Galway, \\ Galway, Ireland. \\ \{mohamed.adel, mahmoud.aliyu, hatem.bensta, adegboyega.ojo\}@insight-centre.org
}

\begin{abstract}
Public policies documents convey strategic directions and framework of actions of government in a particular sector. For most societal challenges, there is a need for government entities at the same and different levels to coordinate their policies and collaborate on the implementations of policies. However, this coordination and collaboration efforts are seriously hampered by the lack of a central repository for public policy documents from which policy makers and researchers can access related policies on a particular topic, industry or group of stakeholders. To address this challenge, this paper describes the development of Vocabulary to underpin the implementation of a shared public policy repository in Europe. The Core Public Policy Vocabulary (CPPV) is developed as a semantic interoperability resource for government organizations for consistent description and documentation of public policies to enable efficient discovery, cross-referencing and analysis of policy documents. We describe our approach, conceptual model, elements of the vocabulary, its implementation and concrete scenarios for the use of the vocabulary.
\end{abstract}

Keywords: Core Public Policy Vocabulary, CPPV, Inter-agency collaboration, Standardisation, Open Policy, Policy Repository, e-Government

\section{Introduction}

Service Delivery and Policy Networks are one of the most common Governance Networks in the public sector in which entities within government and outside government work together to tackle complex societal challenges [1]. Collaboration in public policy making is pivotal to coherence of government programs in general. Policy coherence entails systematic promotion of mutually reinforcing policy actions across government departments and agencies creating synergies towards achieving the agreed objectives [2]. In the context of Sustainable Development, integrated policy making and coherence aims to foster synergies across economic, social and environmental policy areas; identifying trade-offs and reconcile domestic and international objectives; and addressing the spill-overs of domestic policies on other countries and on future generations ( ibid). 
There are three main approaches towards assessing the coherence of public policies. These include: 1) Analytical approaches: Modelling of cause-and-effect relations; 2) Participatory approaches: Involving stakeholders; and 3) Knowledge management: collection and processing of data ${ }^{1}$. The knowledge management dimension requires some form of standardization in collecting the relevant data on policies to be stored in the knowledge base. Standardisation here entails specifying some minimum agreed information to be provided by different parties (i.e. government agencies) responsible for producing and publishing public policies. For instance, the European Commission's Interoperability Solutions for Public Administrations (ISA) provides a number of similar standards - Core vocabularies about organizations, person, public services, locations, public organizations etc.; to facilitate semantic interoperability among public administrations across the European Union [3]. These vocabularies are data models which capture the fundamental characteristic of an entity in a context-neutral fashion thus enabling public administration to use these models as basis for information exchange, data integration and publishing of open data or information ${ }^{2}$.

The development of the vocabulary - Core Public Policy Vocabulary (CPPV) presented in this article was motivated by the lack of a public repository or knowledge base of open public policies and the unavailability of existing standards in the form of ontologies, schema or data models that could be adapted to underpin the development of such repository. To address this problem, we have developed a conceptual model and a vocabulary to implement the model as a basis for a public policy repository or knowledge base.

This rest of the paper is structured as follows: Sections 2 describes some of the basic concepts underpinning CPPV vocabulary. The methodology employed for the development of the vocabulary is presented in Section 3 while the details of the vocabulary are provided in Section 4. Section 5 discusses the application scenario of the vocabulary followed by some final discussions in Section 6 .

\section{Concepts}

This section briefly explains some core concepts underpinning the CPPV vocabulary. It describes the concept of public policies in Section 2.1 and the notion of vocabularies and ontologies in Section 2.2.

\subsection{Public Policies}

A Public Policy is a commitment made by a government (or inter-governmental) entity to accomplish a single or set of objectives. It could also be described as " $a$ principled guide to action taken by the administrative executive branches of the state

\footnotetext{
${ }^{1} \mathrm{http} / / / \mathrm{www}$. liaise-kit.eu/ia-method/methods-analyse-coherence-policies

2 https://ec.europa.eu/isa2/solutions/core-vocabularies en
} 
with regard to a class of issues in a manner consistent with law and institutional customs" "3 . A policy might be detailed using laws or other formal documents to discuss the institutional settings e.g. executing organization, and rewards/fines system [4]. A Public policy is could also as the aggregation of actions, legal acts, governing measures, duties, sequences of operations and resource allocation precedence that are completed, in the 'public's' name [5].

Examples of policies include regulatory policies, redistributive policies, fiscal policies and monetary policies [6]. Regulatory policies allow the government to exert control over the conduct of certain activities. The most obvious examples of regulation techniques include civil and criminal penalties for certain behaviors. Redistributive policies are used for managing the economy as a whole. The techniques of control involve fiscal (tax) and monetary (supply of money policies. Fiscal techniques employ tax rates and government spending to affect total or aggregate demand. Each particular approach to taxing or spending can have a different impact on the overall economy, so political entrepreneurs often propose or initiate policies with the goal of achieving specific impacts. Monetary policies attempt to regulate the economy by changing the rate of growth of the money supply or manipulating interest rates.

Public policies documents are usually published on government agencies websites responsible for their development and implementation. In exceptional cases (e.g. the UK government ${ }^{4}$ ), policy documents are accessible through one central point. Even when this is the case, cross-analysis and linking of these policies is not possible.

\subsection{Vocabularies \& Public Policies}

Vocabularies are represents the definitions of concepts and their relationships in a certain domain of interest. Practically, vocabularies represent the base component for the semantic web inferencing framework [7]. Vocabularies also enable semantic integration and interoperation and understanding of the domain [8]. Ontologies are more complex form of vocabularies which are described formal explicit specification of a shared conceptualization [9].

Ontologies are employed to perform following: organizing and structuring information, reasoning and problem solving, semantic indexing and search, semantic integration and interoperation and understanding of the domain [8]. Ontologies like vocabularies do not only describe the data model, it also supports the specification of concrete exemplars (also called individuals) of such models.

There have been past efforts in describing public policies using other methods of formalism associated with the subject of policy modelling. For instance in the OCOPOMO (Open Collaboration Policy Modelling) project, the goal was to engage stakeholders in policy making [10]. Public policies such as renewable energy policy of the Kosice region in Slovakia, housing policy of the city of London or the

\footnotetext{
${ }^{3}$ https://www.jstor.org/topic/public-policy/

${ }^{4}$ https://www.gov.uk/government/policies
} 
distribution of structural funds in the Campania region in Italy were analysed and modelled. OCOPOMO provided so-called Consistent Conceptual Description for these policy cases. The OCOPOMO framework also supported semi-automatic transformation of conceptual policy descriptions in the CCD into formal policy models. In a second example the Open Preservation Data project [11], designed a policy vocabulary to control the digital preservation process and as enabling preservation systems to collaborate more effectively. Thirdly, some standardization efforts in the United States on publishing strategy related documents and performance plans of government agencies have produced the Strategy Markup Language (StratML) [12]. StratML was designed to enable the publishing of these documents in open and machine readable format.

However, so far, none of these efforts have resulted in a scalable public policy standard that could be adopted to underpin (pan European) Public Policy repository.

\section{Methodology}

This section describes our overall approach in the development of the Core Public Policy Vocabulary. There are popular alternatives to developing vocabularies. The first is to adopt a lightweight version of ontology development approaches. The second approach is to adopt the more general conceptual modelling process. We adopted the latter approach due to the importance we gave the underpinning conceptual model for the vocabulary.

Conceptual modelling (CM) is the elicitation and the representation of the general knowledge that an information system operating in a specific domain needs to know $[13,14]$. In particular, conceptual modelling aims at representing static (e.g., objects, entities) and dynamic phenomena (e.g., events and processes) in a particular domain [15]. Conceptual modelling encompasses four elements [15]:

CM grammar [16] (or CM notation [17]) that provides a set of constructs and rules showing how to combine the constructs in order to model the real world domain [15]. The IS literature includes a vast variety of conceptual modelling grammars including data oriented, process oriented and object-oriented ones, [13, 15, 17-20].

CM method (or modelling technique $[17,21]$ that prescribes how to map the real phenomena of the domain into a model of the domain [15]. A rather limited number of CM methods exist in the literature [15, 18].

CM script (or conceptual schema $[13,14,17,18,22]$ or conceptual model [17, 18 ] is the output of the CM method and is constructed using a CM grammar [15]. It is usually one (or more) diagrams [18] depicting the domain's concepts. A great variety of conceptual scripts have been proposed in the literature [13, 15, 18, 21, 23].

$\mathrm{CM}$ context, which is the setting in which conceptual modelling occurs and scripts are used.

Guide by the above Conceptual modelling framework, we started by developing concrete scenarios and general use cases for the vocabulary. Following this we analysed over 20 well documented public policy documents across different sectors and from different public administration cultures in Europe. These documents serve 
as primary sources of requirements for what could constitute core elements in describing the public policies (as shown in Fig. 1).

A minimalist orientation was adopted in identifying these core elements in line with the guiding principles for the European Commission's Core Vocabulary5 as agreements are easier when the standards are simple enough to enable exchange and concomitantly allow for possible extensions by individual collaborating government entities using the standards.

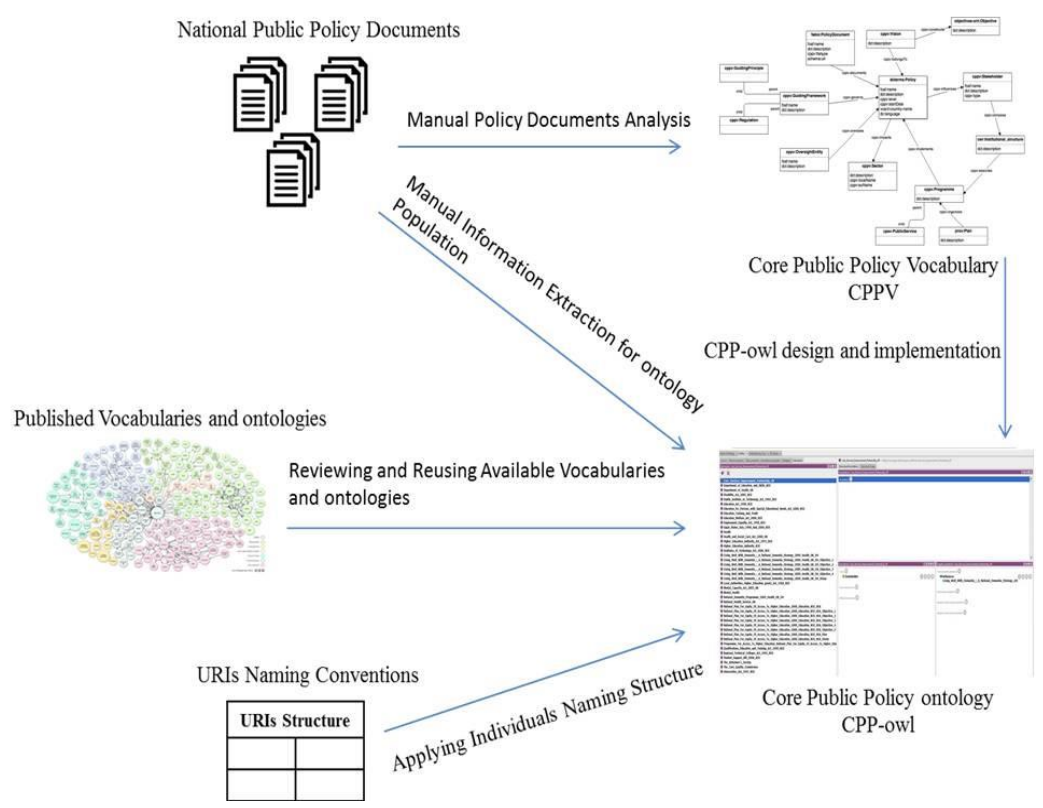

Fig. 1. The Core Public Policy Vocabulary Modeling Methodology

\section{Core Public Policy Vocabulary}

This section provides some details about the elements of the CPPV vocabulary. Section 4.1 describes the conceptual model while

\subsection{Conceptual Model}

The Core Public Policy Vocabulary (CPPV) contains the following classes and properties to model elements public policies resulting from the process described

${ }^{5}$ https://joinup.ec.europa.eu/site/core_vocabularies/Core_Vocabularies_user_handbook/ISA $\% 2$ 0Hanbook $\% 20$ for $\% 20$ using $\% 20$ Core $\% 20$ Vocabularies.pdf 
above. Elements were included in the vocabulary after detailed analysis of their necessity in being part of the core or minimal set. Subsequently, the Core Public Policy Ontology was manually populated (CPP-owl)6 by extracting and mapping information from sample public policies as shown in Fig. 5. A detailed description of the CPPV elements is listed in tables 1 (the main classes) and 2 (properties). The definitions of these elements are provided in respective tables.

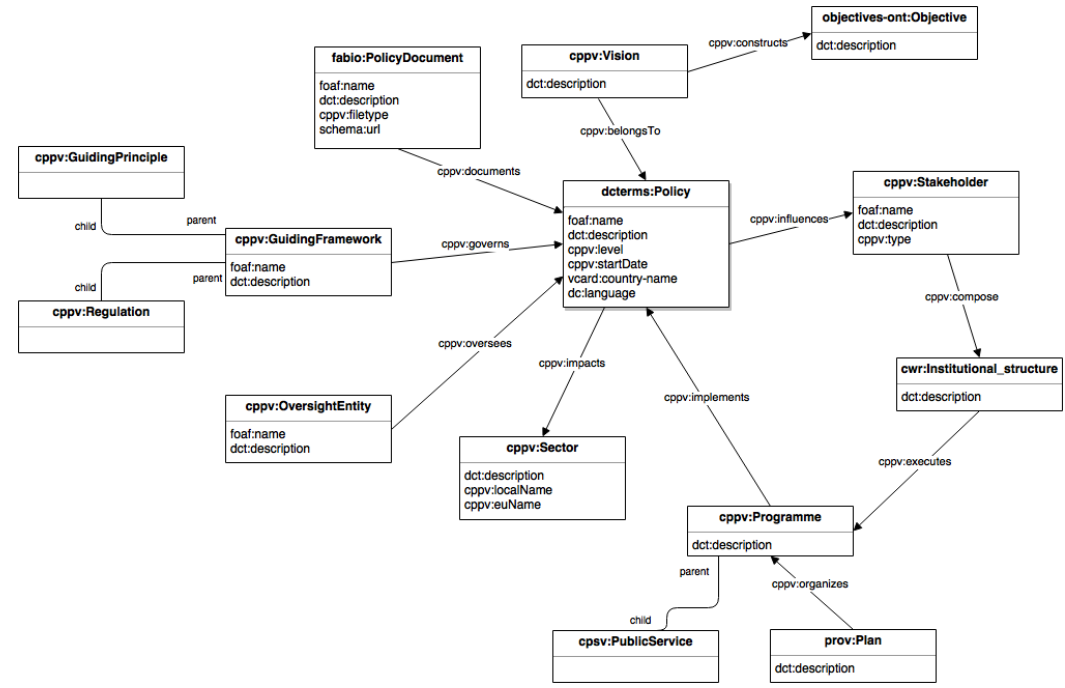

Fig. 2 Core Public Policy Vocabulary (CPPV) Conceptual Model

Table 1. CPPV Classes i.e. Concepts

\begin{tabular}{|c|c|c|}
\hline Class & Description & URI \\
\hline cppv:GuidingFramework & $\begin{array}{l}\text { The Parent Class for the Guiding Principle } \\
\text { and the Regulation. }\end{array}$ & $\begin{array}{l}\frac{\text { http://www.ego }}{\text { v.deri.ie/cppv.o }} \\
\text { wl\#GuidingFra } \\
\text { mework }\end{array}$ \\
\hline cppv:GuidingPrinciple & $\begin{array}{l}\text { The foundation of every organization. } \\
\text { They define what is truly important for its } \\
\text { success. }\end{array}$ & $\begin{array}{l}\text { http://www.ego } \\
\text { v.deri.ie/cppv.o } \\
\text { wl\#GuidingPri } \\
\text { nciple }\end{array}$ \\
\hline cwr:institutional_structure & $\begin{array}{l}\text { Explicit and implicit institutional rules and } \\
\text { policies designed to provide a structure } \\
\text { where various work roles and } \\
\text { responsibilities are delegated and } \\
\text { coordinated. source:(cwr) }\end{array}$ & $\begin{array}{l}\frac{\text { http://www.fao }}{\text { org/aims/aos/c }} \\
\text { wr.owl\#institut } \\
\text { ional structure }\end{array}$ \\
\hline objectives-ont:Objectives & $\begin{array}{l}\text { Things policy actions set out or are } \\
\text { intended to attain or accomplish. Top level } \\
\text { class for Goals and Objectives. } \\
\text { source:(objectives-ont) }\end{array}$ & $\begin{array}{l}\frac{\text { http://www.da }}{\text { ml.org/experim }} \\
\text { ent/ontology/o } \\
\text { bjectives-ont\# } \\
\text { Objectives }\end{array}$ \\
\hline
\end{tabular}

${ }^{6} \mathrm{http://vmogi01.deri.ie/egovcppv/}$ 


\begin{tabular}{|c|c|c|}
\hline cppv:OversightEntity & $\begin{array}{l}\text { A distinct or independent body charged } \\
\text { with supervision and observation of policy } \\
\text { implementation. }\end{array}$ & $\begin{array}{l}\frac{\text { http://www.ego }}{\text { v.deri.ie/cppv.o }} \\
\text { wl\#OversightE } \\
\text { ntity }\end{array}$ \\
\hline terms2:PeriodOfTime & $\begin{array}{l}\text { An interval of time that is named or } \\
\text { defined by its start and end dates. } \\
\text { source:(dublin core) }\end{array}$ & $\begin{array}{l}\frac{\underline{\text { http://dublincor }}}{\text { e.org/document }} \\
\frac{\text { s/2012/06/14/d }}{\text { cmi-terms/?v=t }} \\
\text { erms\#PeriodOf } \\
\text { Time }\end{array}$ \\
\hline prov:Plan & $\begin{array}{l}\text { A detailed proposal for doing or achieving } \\
\text { something. A plan is an entity that } \\
\text { represents a set of actions or steps intended } \\
\text { by one or more agents to achieve some } \\
\text { goals. source:(prov) }\end{array}$ & $\begin{array}{l}\text { http://www.w3. } \\
\underline{\text { arg/ns/prov\#P1 }}\end{array}$ \\
\hline cppv:Poilcy & $\begin{array}{l}\text { A combination of law, rules and guidelines } \\
\text { that determine or control results, } \\
\text { management and information usage - that } \\
\text { designs the role of information in a } \\
\text { community. }\end{array}$ & $\begin{array}{l}\text { http://www.ego } \\
\text { v.deri.ie/cppv.o } \\
\text { wl\#Policy }\end{array}$ \\
\hline fabio:PolicyDocument & $\begin{array}{l}\text { A document embodying a policy that } \\
\text { descibes and defines how something } \\
\text { should be done. source:(fabio) }\end{array}$ & $\begin{array}{l}\text { http://purl.org/s } \\
\text { par/fabio/Polic } \\
\text { yDocument }\end{array}$ \\
\hline cppv:Programme & $\begin{array}{l}\text { A planned series of future events or } \\
\text { performances. Structures for implementing } \\
\text { and executing policies. }\end{array}$ & $\begin{array}{l}\frac{\text { http://www.ego }}{\text { v.deri.ie/cppv.o }} \\
\text { wl\#Programme }\end{array}$ \\
\hline cpsv:PublicService & $\begin{array}{l}\text { This class represents the service itself. A } \\
\text { public service is the capacity to carry out a } \\
\text { procedure and exists whether it is used or } \\
\text { not. It is a set of deeds and acts performed } \\
\text { by or on behalf of a public agency for the } \\
\text { benefit of a citizen, a business or another } \\
\text { public agency. source:(cpsv) }\end{array}$ & $\begin{array}{l}\text { http://purl.org/ } \\
\text { vocab/cpsv\#Pu } \\
\text { blicService }\end{array}$ \\
\hline cppv:Regulation & $\begin{array}{l}\text { The system of rules which a particular } \\
\text { country or community recognizes as } \\
\text { regulating the actions of its members and } \\
\text { which it may enforce by the imposition of } \\
\text { penalties. }\end{array}$ & $\begin{array}{l}\frac{\text { http://www.ego }}{\text { v.deri.ie/cppv.o }} \\
\text { wl\#Regulation }\end{array}$ \\
\hline cppv:Sector & $\begin{array}{l}\text { A distinct part, especially of society or of a } \\
\text { nation's economy that is impacts or } \\
\text { impacted by the public policy. }\end{array}$ & $\begin{array}{l}\text { http://www.ego } \\
\text { v.deri.ie/cppv.o } \\
\text { wl\#Sector }\end{array}$ \\
\hline cppv:Stakeholder & $\begin{array}{l}\text { All key parties influenced or affected by } \\
\text { the implementation of a policy. }\end{array}$ & $\begin{array}{l}\text { http://www.ego } \\
\text { v.deri.ie/cppv.o } \\
\text { wl\#Stakeholder } \\
\end{array}$ \\
\hline cppv:Vision & $\begin{array}{l}\text { An organisation's road map, indicating } \\
\text { both what it wants to become and guiding } \\
\text { transformational initiatives by setting a } \\
\text { defined direction for growth or } \\
\text { achievement. }\end{array}$ & $\begin{array}{l}\text { http://www.ego } \\
\text { v.deri.ie/cppv.o } \\
\underline{\text { wl\#Vision }}\end{array}$ \\
\hline
\end{tabular}


Table 2. CPPV Object Properties i.e. Relations

\begin{tabular}{l|l|l|l}
\hline Object Property & Domain & Range & Is inverse of \\
\hline belongsTo & Vision & Policy & hasVision \\
\hline compose & Stakeholder & institutional_structure & composedOf \\
\hline constructs & Vision & Objective & constructedBy \\
\hline documents & PolicyDocument & Policy & documentedby \\
\hline executes & institutional_structure & Programme & executedBy \\
\hline governs & GuidingFramework & Policy & governedBy \\
\hline impacts & Policy & Sector & isImpactedBy \\
\hline implements & Programme & Policy & implementedBy \\
\hline influences & Policy & Stakeholder & influencedBy \\
\hline organizes & Plan & Programme & organizedBy \\
\hline oversees & OversightEntity & Policy & overseenBy \\
\hline relatedTo & Thing & Thing & relatedTo \\
\hline
\end{tabular}

Policy coordination and coherence can be analysed and effected through a number of relationships such as impacts which specified which sectors are impacted by a policy, implements which indicates which programmes are linked to specific policies or governs which specifies a legislation or higher level framework that binds a set of policies. All these properties with a supporting Uniform Resource Identifier (URI) strategy provide strong mechanism for linking in a policy ecosystem.

\subsection{Vocabulary Implementation}

The above vocabulary was implemented in number of ways. First, we created an ontology based on this vocabulary in Protégé (one of the most popular open source ontology editor and management tool) so that basic analysis and reasoning could be performed on exemplar policies. By capturing the policies in Protégé, a linked data of public policy could be generated and published as open data on the government open data portals. Figure 3 below the screen shot of the implementation,

In our second implementation, the vocabulary was on the employed for publishing our sample policies as open policies on the popular Comprehensive Knowledge Archive Network (CKAN) ${ }^{7}$ platform developed by the Open Foundation. CKAN is the most popular open data platform available. CKAN in our instance represents an open policy repository providing one central point of access to the public and policy makers. In addition to the vocabulary, the use of standard code lists and entity identifiers are required to fully link up the published policies.

\footnotetext{
${ }^{7}$ https://ckan.org/this
} 


\section{Applications}

This section describes in more details how the vocabulary could be exploited to enable collaboration among government entities in the implementation of public policies. Following this, we present a few other application scenarios of the CPPV vocabulary and discuss how it could be formally adopted.

\subsection{The Collaboration Scenario}

Let's assume the availability of the above CKAN based Open Policy Repository in a Public Administration jurisdiction. In addition, we could assume that all public authorities are mandated to publish the policies on the Open Policy Platform. Supposing the Environment department would like to design a policy to address the increasing level of air pollution in a city produced by cars. One of the policy makers in the Environment searches for "air pollution" on the policy repository to identifier other policies that may be addressing issues related to air pollution. He discovers that the Trade and Transport ministries are two other departments interested on the issue. The reference from the Trade department referred to levels of emissions permitted from imported cars and the Transport department reference was linked to the road worthiness assessment. The policy officer from the environment investigates the programmes associated with respective policies and sets up meetings to better understand how the new policy to be design could leverage the existing programs. The officer also wishes to know how the environment department could participate in pollution related programs of these other departments.

\subsection{Other Application Scenarios}

Here we highlight two other application scenarios for the CPPV vocabulary.

Scenario 2: Semantic Policy Search Engine: Researchers and Business users of a $\mathrm{CPPV}$ ontology based search engine to browse the public policies or run complex queries, to discover opportunities in a market. Example: Firm $\mathrm{X}$ is specialized in the energy sector; they would like to extend their business to Country Y. To get a better understanding of the market they need to review Country Y's energy policies and related policies using a search engine such as the semantic policy search engine.

Scenario 3: "Policy learning" - During the policy making or policy update processes, governments may review policies from the Open Public Policy platform to find best practices or certain policy aspects to adopt. Example: Government $Y$ is developing a new Health policy and would want to review different Health polices implemented in the European Union, query for certain aspects of the Health policies to improve their policy decisions. 


\subsection{Formal Adoption of the Core Public Policy Vocabulary}

Finally, we briefly highlight the vision for the adoption of the vocabulary. Currently, the vocabulary is being reviewed by experts involved in public sector information modelling practices in Ireland, Scotland and UK, semantic interoperability and standards in Europe for staged adoption. After the adoption by a these governments, the follow-up steps entails submitting the vocabulary to the European Commission's ISA programme as a candidate Core Vocabulary.
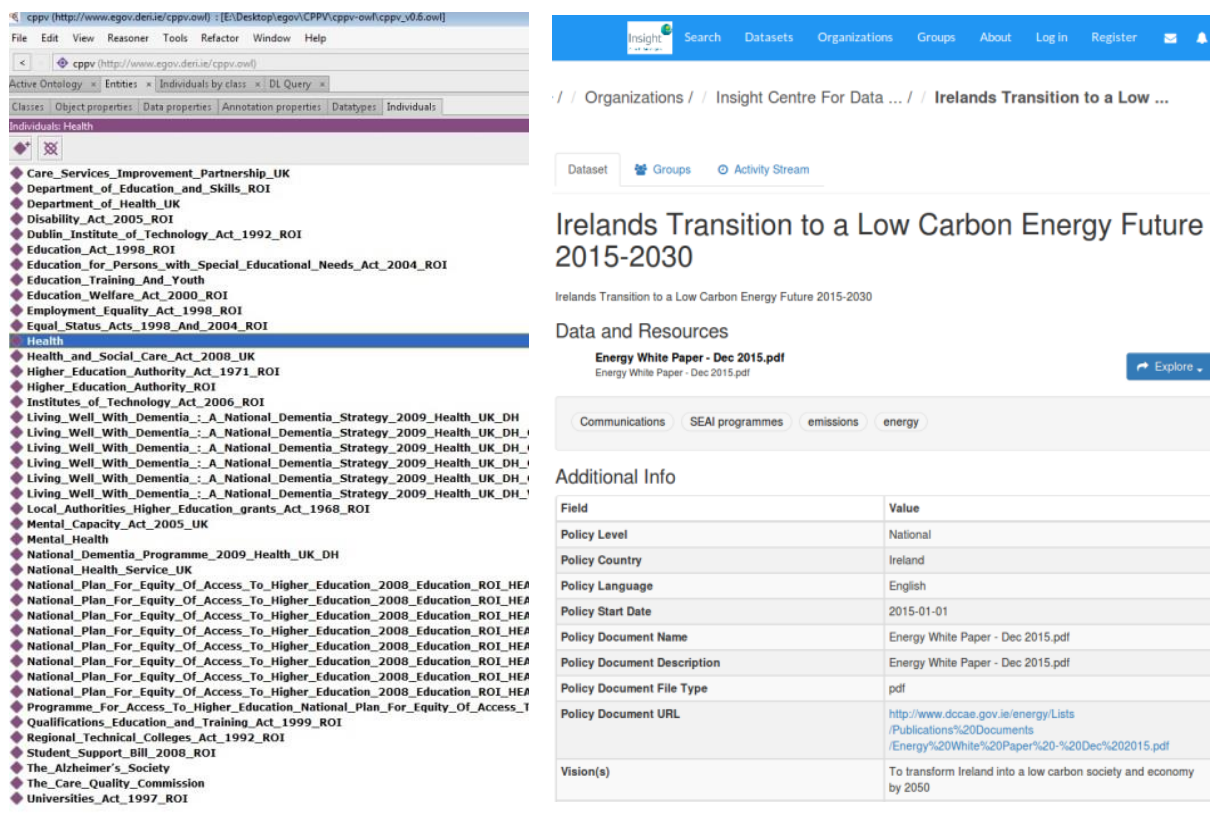

Fig. 3 Core Public Policy Vocabulary Implementations in Protégé and CKAN

\section{Conclusion}

Our work was motivated the lack of the of central repository for government policies in Europe and the underpinning semantic data model or vocabulary to facilitate the inter-linking and exchange of public policies in the European Public Administration Ecosystem. The unavailability of such infrastructure makes the collaboration among public agencies and development of coherent public policies difficult. In addressing this challenge, we have developed a public policy ontology guided by the principles driving the ISA's Core Vocabulary initiatives. Our Core Public Policy Vocabulary complements existing core vocabularies and reuses elements of these vocabularies. 
We are currently in the second stage of the third-party country expert review process of the vocabulary. We intend to develop many uses cases to demonstrate policy collaboration opportunities afforded by the CPPV. In addition, we plan to provide reference implementation using other technologies such as Semantic Media Wiki or Wiki Data ${ }^{8}$. In the near future, we intend to propose the CPPV vocab as a candidate ISA Core Vocabulary.

\section{References}

1. Ojo, A., Mellouli, S.: Deploying governance networks for societal challenges. Gov. Inf. Q. (2016).

2. OECD: Policy coherence for development. (2010).

3. ISA: Core Vocabularies Specification. (2012).

4. CDM - Executive Board: Definitions of policy and programme of activities, (2001).

5. Siobhan, L.: Community Development Development. (2006).

6. Cochran, C.L., Malone, E.F.: Public Policy:Perspectives and Choices. (2005).

7. W3: Ontologies - W3C, https://www.w3.org/standards/semanticweb/ontology.

8. Valente, A.: Types and roles of legal ontologies. In: Law and the semantic web. pp. 65-76. Springer (2005).

9. Gruber, T.R.: A translation approach to portable ontology specifications. Knowl. Acquis. 5, 199-220 (1993).

10. Wimmer, M.A., Furdik, K., Bicking, M., Mach, M., Sabol, T., Butka, P.: Open Collaboration in Policy Development: Concept and Architecture to integrate scenario development and formal policy modelling. In: Empowering open and collaborative governance. pp. 199-219. Springer (2012).

11. Kulovits, H., Kraxner, M., Plangg, M., Becker, C., Bechhofer, S.: Open Preservation Data: Controlled vocabularies and ontologies for preservation ecosystems. Proc. 10th Int. Conf. Preserv. Digit. Objects (IPRES 2013). (2013).

12. Strategy Markup Language Committee: stratml, http://stratml.us.

13. Olivé, A., Cabot, J.: A research agenda for conceptual schema-centric development. In: Conceptual Modelling in Information Systems Engineering. pp. 319-334. Springer (2007).

14. Rolland, C.: Capturing system intentionality with maps. In: Conceptual modelling in Information Systems engineering. pp. 141-158. Springer (2007).

15. Wand, Y., Weber, R.: Research commentary: information systems and conceptual modeling a research agenda. Inf. Syst. Res. 13, 363-376 (2002).

16. Wand, Y., Monarchi, D.E., Parsons, J., Woo, C.C.: Theoretical foundations for conceptual modelling in information systems development. Decis. Support Syst. 15, 285-304 (1995).

17. Mylopoulos, J., Chung, L., Yu, E.: From object-oriented to goal-oriented requirements analysis. Commun. ACM. 42, 31-37 (1999).

18. Rolland, C.: Information Systems and Web Information Systems: A Methodological Perspective. In: Information Technology and Communication at the Dawn of the New Millennium. p. 1 (2000).

19. Olle, T.W., Sol, H.G., MacDonald, I.G.: Information Systems Methodologies; A Framework for Understanding. Addison-Wesley Longman Publishing Co., Inc. (1991).

${ }^{8}$ https://www.wikidata.org/wiki/Wikidata:Main_Page 
20. Rolland, C., Prakash, N.: From conceptual modelling to requirements engineering. Ann. Softw. Eng. 10, 151-176 (2000).

21. Davies, I., Green, P., Rosemann, M., Indulska, M., Gallo, S.: How do practitioners use conceptual modeling in practice? Data Knowl. Eng. 58, 358-380 (2006).

22. Bubenko Jr, J.A.: From information algebra to enterprise modelling and ontologies A historical perspective on modelling for information systems. In: Conceptual Modelling in Information Systems Engineering. pp. 1-18. Springer (2007).

23. Frisse, M.E., Johnson, K.B., Nian, H., Davison, C.L., Gadd, C.S., Unertl, K.M., Turri, P.A., Chen, Q.: The financial impact of health information exchange on emergency department care. J. Am. Med. Informatics Assoc. 19, 328-333 (2012). 